\title{
Nucleophilic reactions at the ring carbons of thiiranium and thiirenium ions. An experimental and theoretical comparison of the $\mathrm{S}_{\mathrm{N}} 2$ and $\mathrm{S}_{\mathrm{N}} 2-$ Vin mechanisms
}

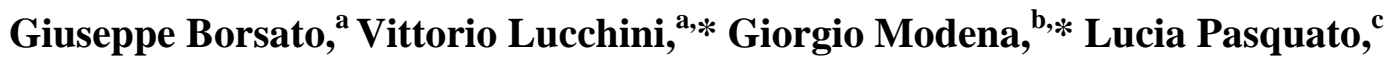 \\ and Alfonso Zambon ${ }^{\mathrm{a}}$ \\ ${ }^{a}$ Dipartimento di Scienze Ambientali, Università di Venezia, Dorsoduro 2137, 30123 Venezia, \\ Italy \\ ${ }^{b}$ Dipartimento di Chimica Organica, Università di Padova, via Marzolo 1, 35131 Padova, Italy \\ ${ }^{c}$ Dipartimento di Scienze Chimiche, Università di Trieste, via Giorgieri 1, 34127 Trieste, Italy \\ E-mail : Giorgio.modena@unipd.it
}

This manuscript is dedicated to Prof. Henry Shine, on the occasion of his $80^{\text {th }}$ birthday

(received 30 Apr 03; accepted 04 June 03; published on the web 26 June 03)

\begin{abstract}
Generally, the bimolecular nucleophilic substitution at the saturated carbon $\left(\mathrm{S}_{\mathrm{N}} 2\right)$ and the mechanistically similar substitution at the vinyl carbon $\left(\mathrm{S}_{\mathrm{N}} 2\right.$-Vin) cannot be quantitatively compared, because of the many interfering steric and electronic factors. The cis and trans rearrangements of trans $c$-2,t-3-di-tert-butyl-r-1-methylthiiranium ion 5a into thietanium ions 6a and $\mathbf{6 b}$ and that of 2,3-di-tert-butyl-1-methylthiirenium ion 7 into thietium ion $\mathbf{8}$ can be be compared both experimentally and computationally. They occur with intramolecular $\mathrm{S}_{\mathrm{N}} 2$ and $\mathrm{S}_{\mathrm{N}} 2$-Vin mechanisms respectively and are both almost exclusively governed by the nucleofugality of the sulfonium leaving group.
\end{abstract}

Keywords: Thiiranium ion, thiirenium ion, thietanium ions, thietium ion, $\mathrm{S}_{\mathrm{N}} 2$ rearrangement, vinyl $\mathrm{S}_{\mathrm{N}} 2$ rearrangement

\section{Introduction}

The bimolecular nucleophilic substitution at the alkyl $\mathrm{sp}^{3}$ carbon occurs exclusively with the $\mathrm{S}_{\mathrm{N}} 2$ mechanism, while that at the aromatic or carboxylic $\mathrm{sp}^{2}$ carbon may occur with many mechanisms (among them the $\mathrm{Ad}_{\mathrm{N}^{-}} \mathrm{E}$ mechanism), but never with the $\mathrm{S}_{\mathrm{N}} 2$ mechanism. On the contrary, the two mechanisms $\left(\mathrm{S}_{\mathrm{N}} 2\right.$ and $\left.\mathrm{Ad}_{\mathrm{N}}-\mathrm{E}\right)$ are both effective in the nucleophilic substitution at the vinyl $\mathrm{sp}^{2}$ carbon atom: although the vast majority of the vinyl substitutions occur with the $\mathrm{Ad}_{\mathrm{N}}-\mathrm{E}$ mechanism, ${ }^{1,2}$ the $\mathrm{S}_{\mathrm{N}} 2$ one (we call it the $\mathrm{S}_{\mathrm{N}} 2$-Vin mechanism) is sometimes recognized. ${ }^{2,3}$ 

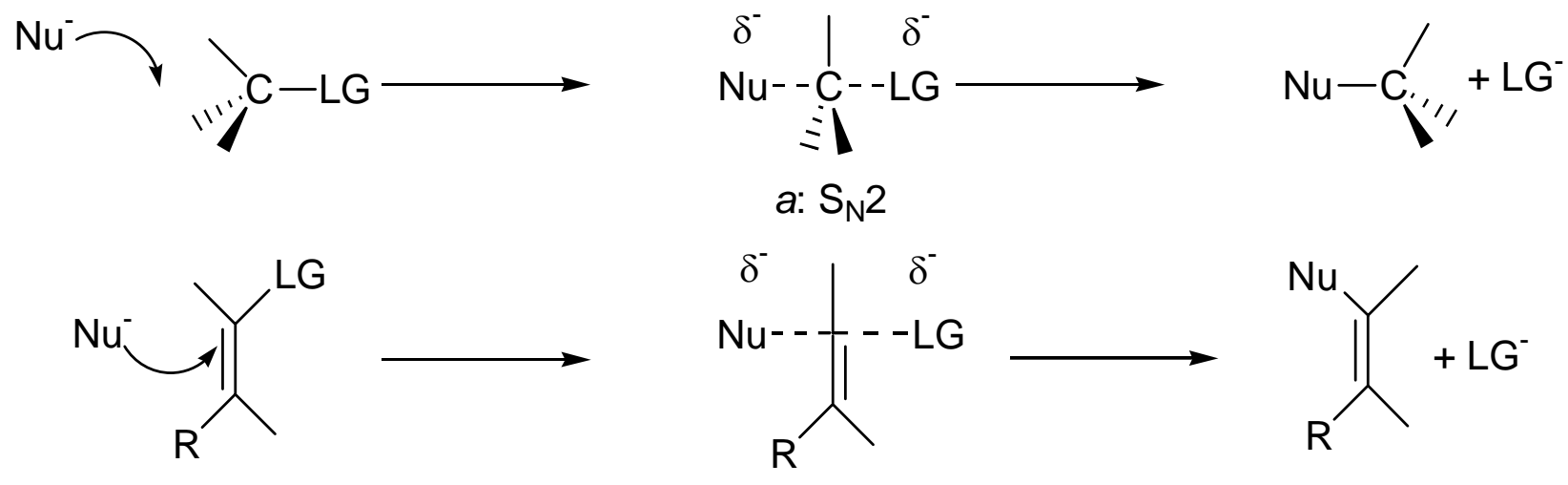

$b: \mathrm{S}_{\mathrm{N}} 2-\mathrm{Vin}$
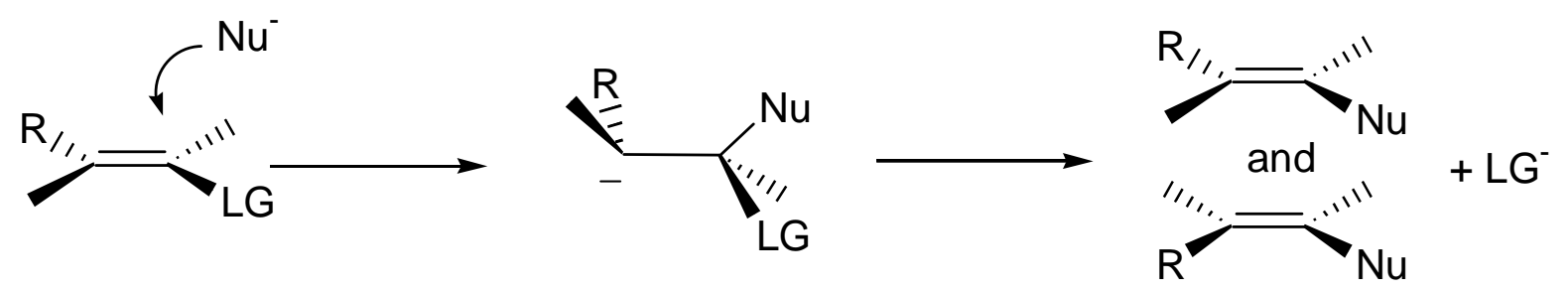

c: $\mathrm{Ad}_{\mathrm{N}} \mathrm{E}$

Figure 1. Bimolecular nucleophilic substitutions at the saturated $\mathrm{sp}^{3}$ and vinyl $\mathrm{sp}^{2}$ carbon atoms.

The classical $\mathrm{S}_{\mathrm{N}} 2$ mechanism is described by the nucleophilic attack at the $\mathrm{sp}^{3}$ carbon along the direction of the leaving group (LG) and from the rear side, goes through a transition state with a pentacoordinated carbon atom, and gives products with inverted stereochemistry at the same atom (case $a$ in Figure 1). In close analogy, the $\mathrm{S}_{\mathrm{N}} 2$-Vin mechanism predicts the nucleophilic attack at the $\mathrm{sp}^{2}$ carbon in the molecular plane and form the rear side of the LG, goes through a planar tetracoordinated transition state, and gives products with inverted stereochemistry (case $b$ in Figure 1). The $\operatorname{Ad}_{\mathrm{N}}-\mathrm{E}$ mechanism is quite different. The nucleophile attacks the vinyl carbon perpendicularly, a tetrahedral intermediate is generated, which evolves to products with stereochemistry ranging from retention to stereoconvergence (case $c$ in Figure 1).

A common requirement for the three mechanisms is the greatest overlap between an occupied orbital (usually the HOMO) of the incoming nucleophile and a vacant orbital (usually the LUMO) at the electrophilic carbon. This requirement dictates the stereochemical outcome of the $\mathrm{S}_{\mathrm{N}} 2$ mechanism and even the choice between the $\mathrm{S}_{\mathrm{N}} 2$-Vin and $\mathrm{Ad}_{\mathrm{N}}-\mathrm{E}$ mechanisms. 


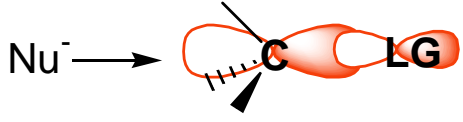

a: $\mathrm{S}_{\mathrm{N}} 2$

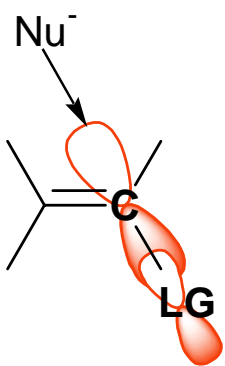

b: $\mathrm{S}_{\mathrm{N}} 2-\mathrm{Vin}$

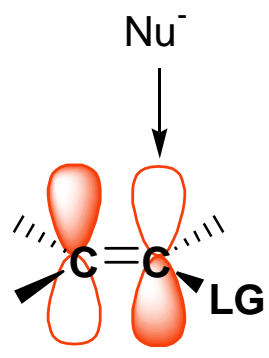

c: $\operatorname{Ad}_{\mathrm{N}}-\mathrm{E}$

Figure 2. Maximal interactions of the nucleophile with the vacant orbital (generally the LUMO): $a$, of a saturated carbon; $b$, with $\sigma$ symmetry, of a vinyl carbon; $c$, with $\pi$ symmetry, of a vinyl carbon.

The most polarized bond at the $\mathrm{sp}^{3}$ carbon is that with the LG; the associated occupied orbital (generally the HOMO) is therefore the one more contributing to the atomic orbital (AO) at the LG. On the contrary, the corresponding vacant orbital (generally the LUMO) is the one most contributing to the $\mathrm{AO}$ at carbon and it is therefore, of the four vacant orbitals, the most diffused at the side opposite to the associated bond. ${ }^{4}$ This explains why the greatest overlap with the incoming nucleophile is assured when the approach of the latter is along the carbon-LG bond and from the rear side (case $a$ in Figure 2).

According to our rationale, ${ }^{5}$ the nucleophilic substitution at the vinyl carbon will occur with the $\mathrm{S}_{\mathrm{N}} 2$-Vin mechanism or with the $\mathrm{Ad}_{\mathrm{N}}$-E mechanism, depending on the nature of the LUMO of the electrophile, either with $\sigma$ symmetry (case $b$ in Figure 2) or with $\pi$ symmetry (case $c$ ). We have in fact found an almost complete correspondence between the symmetry, $\sigma$ or $\pi$, of the LUMO of a series of vinyl systems with a proper LG, and the stereochemical results of nucleophilic substitution reactions performed on them.

\section{Comparison of the $\mathrm{S}_{\mathrm{N}} 2$ and $\mathrm{S}_{\mathrm{N}} 2$-Vin Mechanisms}

The analysis of the diagrams $a$ and $b$ in Figure 2 highlights the close similarity of the $\mathrm{S}_{\mathrm{N}} 2$ and $\mathrm{S}_{\mathrm{N}} 2$-Vin mechanisms. In principle, a quantitative comparison between the two mechanisms can be proposed. The comparison is however not easily accomplished: the first obstacle is the reduced number of kinetic determinations of vinyl substitutions that effectively occur with the $\mathrm{S}_{\mathrm{N}} 2$-Vin mechanism. We illustrate in Figure 3 (cases $b$ and $d$ ) two occurrences where the inplane $\mathrm{S}_{\mathrm{N}} 2$-Vin attack with complete configurational inversion is compulsory or preferred. In these systems the nucleophile or the LG are immediately bonded to the other terminus of the olefinic bond. ${ }^{6}$ The situations are compared with those relative to the $\mathrm{S}_{\mathrm{N}} 2$ susbtitution at the alkyl carbon (cases $a$ and $c$ ).

The cases $b$ and $d$ differ as for one important point: while the geometrical constraint in $b$ compels the nucleophile to the in-plane $\mathrm{S}_{\mathrm{N}} 2$-Vin attack, the attack of the nucleophile to vinyl carbon in $d$ can be either in-plane $\left(\mathrm{S}_{\mathrm{N}} 2-\mathrm{Vin}\right)$ or perpendicular $\left(\mathrm{Ad}_{\mathrm{N}}-\mathrm{E}\right)$.

The situation described by case $b$ is encountered in the solvolysis of vinyl substrates with participation of $\beta$-thio, ${ }^{7} \beta$-iodine ${ }^{8}$ or $\beta$-aryl. ${ }^{9}$ Only in the case of the solvolysis of some $\beta$ - 
thiovinyl substrates, kinetic data are available that can be compared with those for the solvolysis of the corresponding $\beta$-thioalkyl substrates. ${ }^{7,10}$

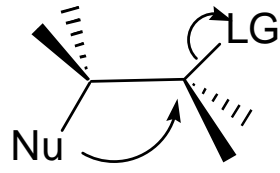

a

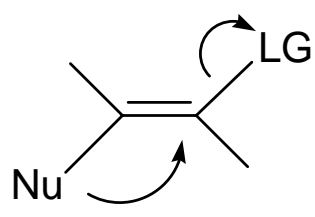

$b$

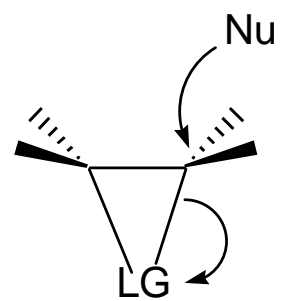

C

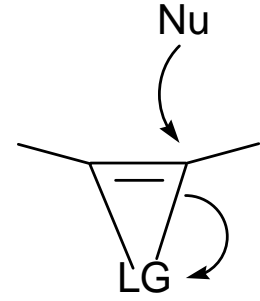

$d$

Figure 3. Intramolecular nucleophilic substitutions at the saturated carbon $(a)$ and at the vinyl carbon (b), where the nucleophile is constrained to the in-plane attack by the geometry. Intermolecular nucleophilic substitution at the saturated carbon $(c)$ and at the vinyl carbon $(d)$, where the LG is bonded to the $\beta$ position.

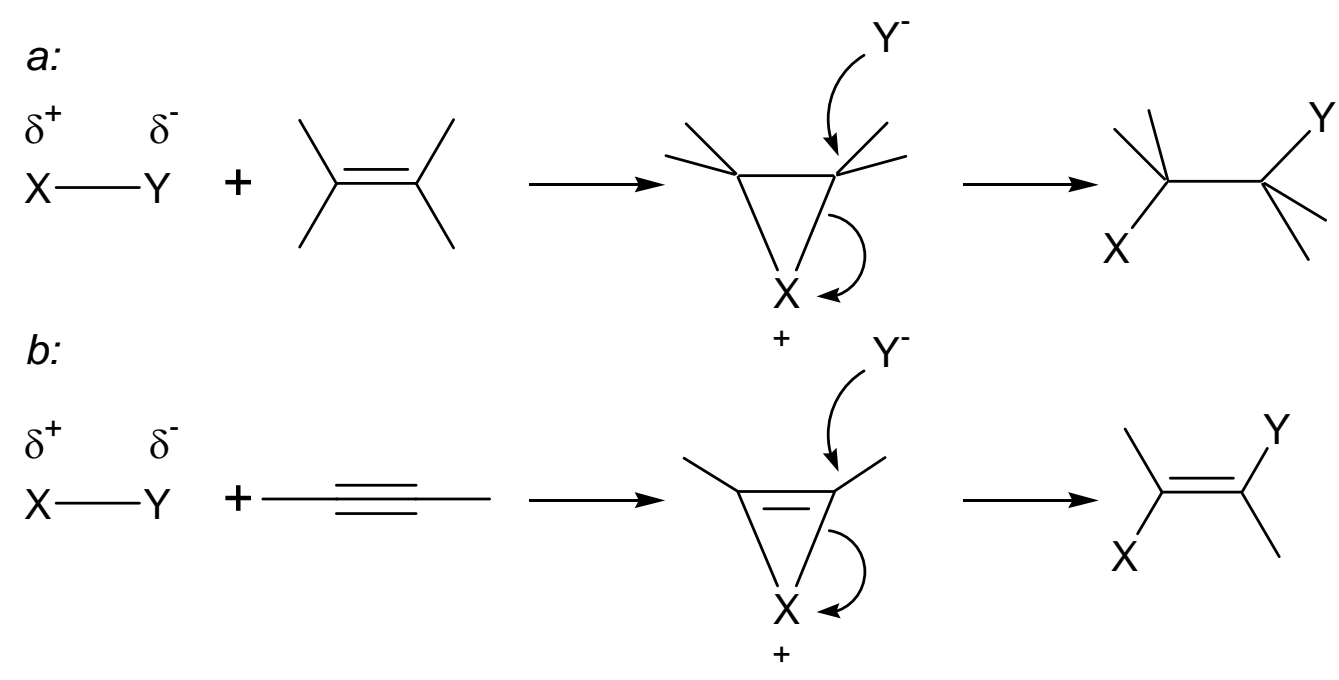

Figure 4. The electrophilic additions to the double and triple $\mathrm{C}-\mathrm{C}$ bonds. The anti modality of the additions requires the in-plane nucleophilic substitutions onto the cyclic intermediates.

On the other hand, the situation of case $d$ is common, and is encountered in the electrophilic additions to the $\mathrm{CC}$ triple bond that occur with generation of $E$ substituted alkenes (case $b$ in Figure 4). Actually, this substitution pattern is rationalized by the intermediacy of irenium ions and by the in-plane anti addition of the nucleophile to this intermediate. It is not generally recognized that this addition is effectively an $\mathrm{S}_{\mathrm{N}} 2-\mathrm{V}$ in substitution. The rate for the electrophilic addition to double and triple CC bonds ${ }^{11}$ cannot be utilized for the purposes of the present research: they do measure the formation of the iranium or irenium intermediates and not the subsequent nucleophilic substitution to them. A useful comparison requires the kinetic measurement of the nucleophilic attack to relatively stable and isolated iranium and irenium ions. Only one such investigation is reported. ${ }^{12,13}$ 
These are the data that we could find in literature.

(a) Some old investigations report the kinetic data for the solvolyses of saturated $\beta$-thioethyl toluenesulfonates $\mathbf{1 a}$ and $\mathbf{1} \mathbf{b}^{14}$ and of $\beta$-thiovinyl trinitrobenzenesulfonates $\mathbf{2} \mathbf{c}$ and $\mathbf{2} \mathbf{d}^{7}$<smiles>[R5]CCO[SeH]([R])=O</smiles>

1

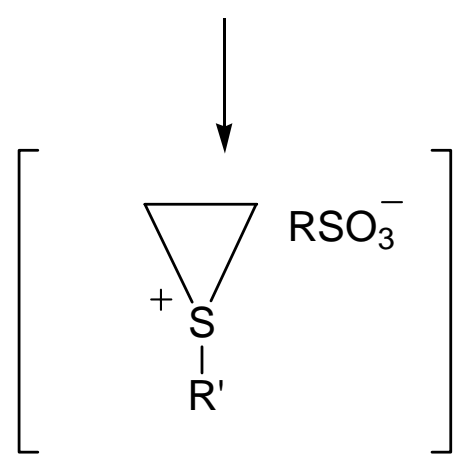

1a: $\mathrm{R}=4-\mathrm{CH}_{3}-\mathrm{C}_{6} \mathrm{H}_{4}, \mathrm{R}^{\prime}=\mathrm{CH}_{3}$ $k=1.97 \times 10^{-3} \mathrm{~s}^{-1}$

1b: $\mathrm{R}=4-\mathrm{CH}_{3}-\mathrm{C}_{6} \mathrm{H}_{4}, \mathrm{R}^{\prime}=\mathrm{C}_{6} \mathrm{H}_{5}$ $k=1.45 \times 10^{-3} \mathrm{~s}^{-1}$

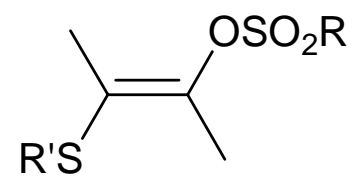

2

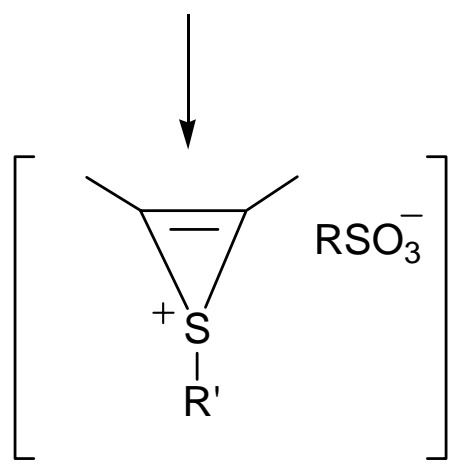

2a: $\mathrm{R}=4-\mathrm{CH}_{3}-\mathrm{C}_{6} \mathrm{H}_{4}, \mathrm{R}^{\prime}=\mathrm{CH}_{3}$ $\left(k=1.62 \times 10^{-8} \mathrm{~s}^{-1}\right)$

2b: $\mathrm{R}=4-\mathrm{CH}_{3}-\mathrm{C}_{6} \mathrm{H}_{4}, \mathrm{R}^{\prime}=\mathrm{C}_{6} \mathrm{H}_{5}$ $\left(k=1.88 \times 10^{-9} \mathrm{~s}^{-1}\right)$

2c: $\mathrm{R}=3,4,6-\mathrm{NO}_{2}-\mathrm{C}_{6} \mathrm{H}_{4}, \mathrm{R}^{\prime}=\mathrm{CH}_{3}$ $k=4.07 \times 10^{-4} \mathrm{~s}^{-1}$

2d: $\mathrm{R}=3,4,6-\mathrm{NO}_{2}-\mathrm{C}_{6} \mathrm{H}_{4}, \mathrm{R}^{\prime}=\mathrm{C}_{6} \mathrm{H}_{5}$ $k=4.70 \times 10^{-5} \mathrm{~s}^{-1}$

Figure 5. Rate constants for the anchimerically assisted solvolyses (at $298 \mathrm{~K}$ ) of the $\beta$-thioethyl sulfonates $\mathbf{1 a}$ and $\mathbf{1 b}$ and of the $\beta$-thiovinyl sulfonates $\mathbf{2 c}$ and $\mathbf{2 d}$. The rate constants for sulfonates $2 \mathbf{a}$ and $\mathbf{2 b}$ are calculated from those of sulfonates $\mathbf{2 c}$ and $\mathbf{2 d}$ (see text).

Both reactions occur with ipso substitution, and therefore with the intermediacy of thiiranium and thiirenium structures (Figure 5).

The kinetic data thus measure the anchimeric assistance of the nucleophilic thio group, as illustrated by schemes $a$ and $b$ in Figure 3. The correct comparison of the kinetic data reported in Figure 5 requires that the LG are the same. No data are available for the solvolyses of the vinyl toluenesulfonates $\mathbf{2 a}$ and $\mathbf{2} \mathbf{b}$, but the data for the solvolyses of the vinyl trinitronebenzenesulfonates $\mathbf{2 c}$ and $\mathbf{2 d}$ can be corrected by the nucleofugality factor ${ }^{13,15}$ of $2.5 \mathrm{x}$ 
$10^{4}$. The resulting data are reported in Figure 5 under parentheses. The $k\left(\mathrm{~S}_{\mathrm{N}} 2\right) / k\left(\mathrm{~S}_{\mathrm{N}} 2-\mathrm{V}\right.$ in $)$ ratios at $298 \mathrm{~K}$ are $1.2 \times 10^{5}$ and $7.7 \times 10^{5}$ for the solvolyses anchimerically assisted by the $\beta$ methylthio and $\beta$-phenylthio groups respectively.

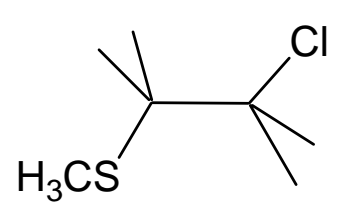

3

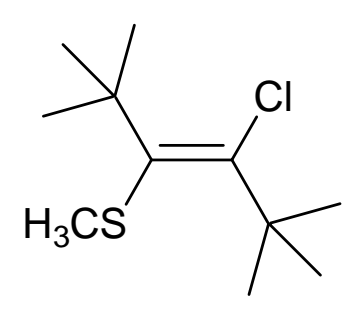

4
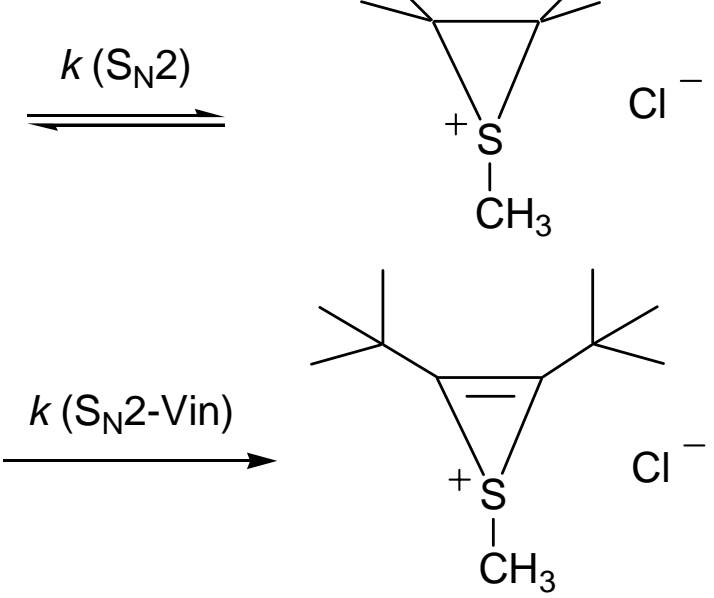

3. $k\left(\mathrm{~S}_{\mathrm{N}} 2\right): 10.0 \mathrm{~s}^{-1}$.

4. $k\left(\mathrm{~S}_{\mathrm{N}} 2-\mathrm{Vin}\right): 1.23 \times 10^{-4} \mathrm{~s}^{-1}$.

Figure 6. Solvolysis rates for the ionization in liquid $\mathrm{SO}_{2}$ at $298 \mathrm{~K}$ of $\beta$-thioethyl chloride 3 and of $\beta$-thiovinyl chloride 4 .

(b) A more recent investigation ${ }^{10}$ reports the kinetic data for the solvolyses in liquid $\mathrm{SO}_{2}$ at $298 \mathrm{~K}$ of the $\beta$-thioethyl chloride 3 and of the $\beta$-thiovinyl chloride 4 , with direct generation of the thiiranium and thiirenium ions. The data, reported in Figure 6 , give a $k\left(\mathrm{~S}_{N} 2\right) / k\left(\mathrm{~S}_{\mathrm{N}} 2-\mathrm{Vin}\right)$ ratio of $8.1 \times 10^{4}$.

(c) The only comparative investigation of nucleophilic substitutions at an iranium ion and at an irenium ion is that illustrated in Figure 7 . The rearrangement ${ }^{12}$ of the trans $c-2, t$-3-di-tertbutyl-r-1-methylthiiranium ion 5a into the thietanium ion $\mathbf{6 a}$ and that ${ }^{13}$ of the 2,3-di-tert-butyl-1methylthiirenium ion 7 into the thietium ion 8 require the anionotropic migrations of one methyl group from the quaternary tert-butyl carbon to the ring $\mathrm{sp}^{3}$ or $\mathrm{sp}^{2}$ carbon. The rearrangement rates at $298 \mathrm{~K}$ in $\mathrm{CD}_{2} \mathrm{Cl}_{2}$ are reported in Figure 7 . We have been able to separately measure in thiiranium ion 5a the rates for the methyl migration from the cis tert-butyl group and from the trans tert-butyl one. Quite clearly, the methyl migration in thiiranium ion 5 a is a case of intramolecular $\mathrm{S}_{\mathrm{N}} 2$ substitution. As for the methyl migration in thiirenium ion 7 , the quantitative gain of the thietium ion 8 as sole rearranged product and the value of the kinetic isotope effect (from comparison with the $\mathrm{CD}_{3}$ migration rate in thiirenium ion 7 perdeuterated at one tert-butyl group) are indicative that it also occurs with the intramolecular $\mathrm{S}_{\mathrm{N}} 2$-Vin mechanism. ${ }^{13}$ The $k\left(\mathrm{~S}_{\mathrm{N}} 2\right) / k\left(\mathrm{~S}_{\mathrm{N}} 2\right.$-Vin) ratios are $1.2 \times 10^{2}$ (for the migration in 5a from the cis tert-butyl) and 6.1 (for the migration from the trans tert-butyl). 
$\mathrm{S}_{\mathrm{N}} 2$

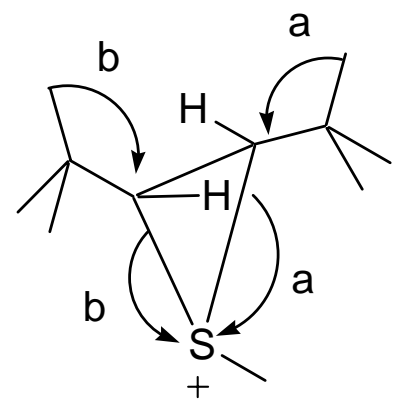

$5 a$

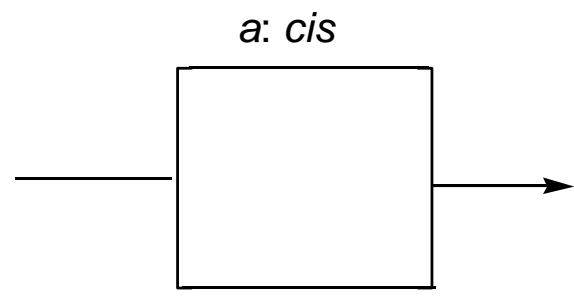

$b$ : trans

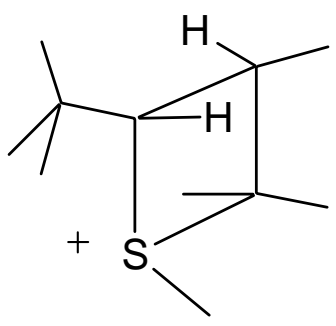

$6 a$

$$
\begin{aligned}
& k_{\text {cis }}: 7.42 \times 10^{-6} \mathrm{~s}^{-1} \\
& k_{\text {trans }}: 3.83 \times 10^{-7} \mathrm{~s}^{-1}
\end{aligned}
$$

$\mathrm{S}_{\mathrm{N}} 2$-Vin

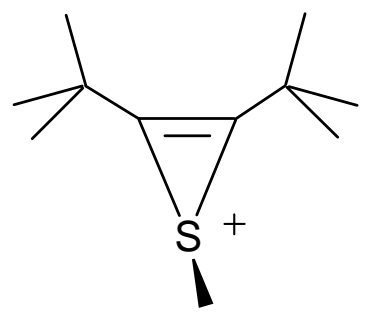

7

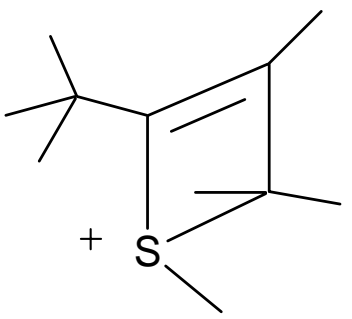

8

$k: 6.30 \times 10^{-8} \mathrm{~s}^{-1}$

Figure 7. Experimental rearrangement rates in thiiranium ion $\mathbf{5 a}$ and thiirenium ion $\mathbf{7 .}$

\section{Factors Affecting the $\mathrm{S}_{\mathrm{N}} 2$ and $\mathrm{S}_{\mathrm{N}} \mathbf{2}-\mathrm{Vin}$ Mechanisms}

The three examples above described give $\mathrm{k}\left(\mathrm{S}_{\mathrm{N}} 2\right) / \mathrm{k}\left(\mathrm{S}_{\mathrm{N}} 2\right.$-Vin) ratios that differ by orders of magnitude and that cannot be accomodated within a simple framework. This fact can be understood, if we consider the numerous factors which may differently interfere with the two $\mathrm{S}_{\mathrm{N}} 2$ and $\mathrm{S}_{\mathrm{N}} 2$-Vin mechanisms: (i) the hindrance exerted by the substituents at the electrophilic carbons, which in $\mathrm{sp}^{3}$ carbons are above or below the plane of the approaching nucleophile, while in $\mathrm{sp}^{2}$ carbons they lie in this same plane; ${ }^{16}$ (ii) the inversion of configuration is a pyramidal inversion at an $\mathrm{sp}^{3}$ carbon atom, and an in-plane inversion at an $\mathrm{sp}^{2}$ carbon atom, which is energetically more costly; ${ }^{17}$ (iii) the nucleofugalities of the LG, also of the same LG, may differ, because of the charge (electrostatic, Mulliken or natural) on it, or because the bonds between the LG and the electrophilic $\mathrm{sp}^{3}$ or $\mathrm{sp}^{2}$ carbon may not have the same length; (iv) the HOMO(nucleophile)-LUMO(electrophile) interactions may differ because of different energy levels and because of different overlap propensities of the LUMOs: an $\mathrm{sp}^{3}$ vacant orbital is in principle more diffuse than an $\mathrm{sp}^{2}$ vacant orbital; (v) the electrophilicity of the $\mathrm{sp}^{3}$ or $\mathrm{sp}^{2}$ carbon 
bound to the LG. This last parameter may be measured by the electrostatic charge, the Mulliken charge or the natural atomic charge.

Table 1. Computed $\left(\mathrm{HF} / 3-21 \mathrm{G}^{*} / / 3-21 \mathrm{G}^{*}\right)$ energies and relevant geometric and electronic parameters for the species involved in the rearrangement processes of thiiranium ions $\mathbf{5 a}$ and $\mathbf{5 b}$ and thiirenium ion 7. Comparison with the relevant experimental parameters

\begin{tabular}{|c|c|c|c|c|c|c|c|}
\hline & hartree & $\mathrm{kcal}_{\mathrm{mol}}^{-1}$ & $\begin{array}{c}\text { Bond } \\
\text { lengths } \\
\AA\end{array}$ & Bond angles & Torsion angles & $\begin{array}{c}E_{\text {LUMO }} \\
\text { hartree }\end{array}$ & $\begin{array}{l}\text { Natural } \\
\text { atomic } \\
\text { charges }\end{array}$ \\
\hline \multicolumn{8}{|c|}{ Rearrangement from cis tert-butyl of $c$-2,t-3-di-tert-butyl-r-1-methylthiiranium ion $\mathbf{5 a :}$} \\
\hline $5 \mathbf{a}$ & -822.994580 & 0.0 & $\mathrm{SC}_{1}: 1.907$ & $\mathrm{SC}_{1} \mathrm{C}_{1}: 68.0$ & $\mathrm{C}_{3} \mathrm{C}_{2} \mathrm{C}_{1} \mathrm{~S}: 178.4$ & -0.03227 & $C_{1}:-0.24$ \\
\hline TS 9a & -822.956080 & 24.2 & & $\mathrm{SC}_{1} \mathrm{C}_{1}: 103.7$ & & & S: 0.68 \\
\hline 6a & -823.011781 & -10.8 & & $\mathrm{SC}_{1} \mathrm{C}_{1}: 90.7$ & & & \\
\hline 11 'a & -822.966600 & 17.7 & & $\mathrm{SC}_{1} \mathrm{C}_{1}: 111.4$ & & & \\
\hline \multicolumn{8}{|c|}{ Rearrangement from trans tert-butyl of $c$-2,t-3-di-tert-butyl-r-1-methylthiiranium ion 5a: } \\
\hline $5 \mathbf{a}$ & -822.994580 & 0.0 & $\mathrm{SC}_{1}: 1.887$ & $\mathrm{SC}_{1} \mathrm{C}_{1}: 66.5$ & $\mathrm{C}_{3}, \mathrm{C}_{2}, \mathrm{C}_{1}, \mathrm{~S}: 167.7$ & -0.03227 & $\mathrm{C}_{1},-0.25$ \\
\hline TS 9b & $-822,951446$ & 27.0 & & $\mathrm{SC}_{1} \mathrm{C}_{1}: 103.7$ & & & S: 0.68 \\
\hline 6b & -823.005944 & -7.1 & & $\mathrm{SC}_{1} \mathrm{C}_{1}: 90.9$ & & & \\
\hline 11'b & -822.957366 & 23.4 & & $\mathrm{SC}_{1} \mathrm{C}_{1}: 108.2$ & & & \\
\hline \multicolumn{8}{|c|}{ Rearrangement of $t$-2,t-3-di-tert-butyl-r-1methylthiiranium ion $\mathbf{5 b}$ : } \\
\hline $5 \mathbf{b}$ & -822.981498 & 0.0 & $\mathrm{SC}_{1}: 1.875$ & $\mathrm{SC}_{1} \mathrm{C}_{1}: 66.5$ & $\mathrm{C}_{3} \mathrm{C}_{2} \mathrm{C}_{1} \mathrm{~S}: 174.4$ & -0.02881 & $\mathrm{C}_{1}:-0.27$ \\
\hline TS 9c & -822.939049 & 26.6 & & $\mathrm{SC}_{1} \cdot \mathrm{C}_{1}: 103.7$ & & & S: 0.73 \\
\hline 6c & -823.003817 & -14.0 & & $\mathrm{SC}_{1} \mathrm{C}_{1}: 89.9$ & & & \\
\hline 11 'c & -822.939049 & 8.9 & & $\mathrm{SC}_{1} \mathrm{C}_{1}: 111.7$ & & & \\
\hline \multicolumn{8}{|c|}{ Rearrangement of 2,3-di-tert-butyl-1-methyl thiirenium ion 7: } \\
\hline 7 & -821.795086 & 0.0 & $\mathrm{SC}_{1}: 1.865$ & $\mathrm{SC}_{1} \mathrm{C}_{1}: 70.1$ & $\mathrm{C}_{3} \mathrm{C}_{2} \mathrm{C}_{1} \mathrm{~S}: 179.5$ & -0.03102 & $\mathrm{C}_{1}: 0.00$ \\
\hline TS 10 & -821.751682 & 27.7 & & $\mathrm{SC}_{1} \mathrm{C}_{1}: 109.1$ & & & S: 0.71 \\
\hline 8 & -821.822372 & -17.1 & & $\mathrm{SC}_{1}{ }^{\prime} \mathrm{C}_{1}: 96.1$ & & & \\
\hline 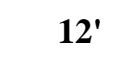 & -822.967340 & 10.6 & & $\mathrm{SC}_{1} \mathrm{C}_{1}: 110.0$ & & & \\
\hline
\end{tabular}

Experimental data $^{\mathrm{a}}$

\begin{tabular}{|c|c|c|c|}
\hline & $\begin{array}{r}\Delta G^{f}{ }_{29} \\
\text { kcal mo }\end{array}$ & & \\
\hline $\mathbf{5 a}$, cis & 24.4 & $\mathrm{SC}_{1}: 1.876$ & $\mathrm{C}_{3} \mathrm{C}_{2} \mathrm{C}_{1} \mathrm{~S}: 174.3$ \\
\hline 5a, trans & 26.2 & $\mathrm{SC}_{1}: 1.860$ & $\mathrm{C}_{3}, \mathrm{C}_{2}, \mathrm{C}_{1}, \mathrm{~S}: 163.5$ \\
\hline 7 & 27.3 & $\mathrm{SC}_{1}: 1.831$ & $\mathrm{C}_{3} \mathrm{C}_{2} \mathrm{C}_{1} \mathrm{~S}: 168.3$ \\
\hline
\end{tabular}

In the case of an intramolecular nucleophile $\beta$ to the LG (cases $a$ and $b$ in Figure 3 ) a further factor should be considered: (vi) the formation of the more strained irenium ring is energetically more costly than that of the iranium ring. In the case of a LG bound to the position $\beta$ to 
electrophilic carbon (cases $c$ and $d$ in Figure 3) an alternative factor may interfere: (vii) the substitution brings about a ring strain release, more pronounced in the case of the opening of the unsaturated irenium ring.

Finally, in the case of the intramolecular nucleophilic displacements of thiiranium ion 5a and thiirenium ion 7, and analogously to other intramolecular substitutions, the following last factor has to be considered: (viii) the degree of antiperiplanarity between the migrating nucleophile and the LG, which, in the case of $\mathbf{5 a}$ and 7 , is related to the rotational preference of the involved tertbutyl group.

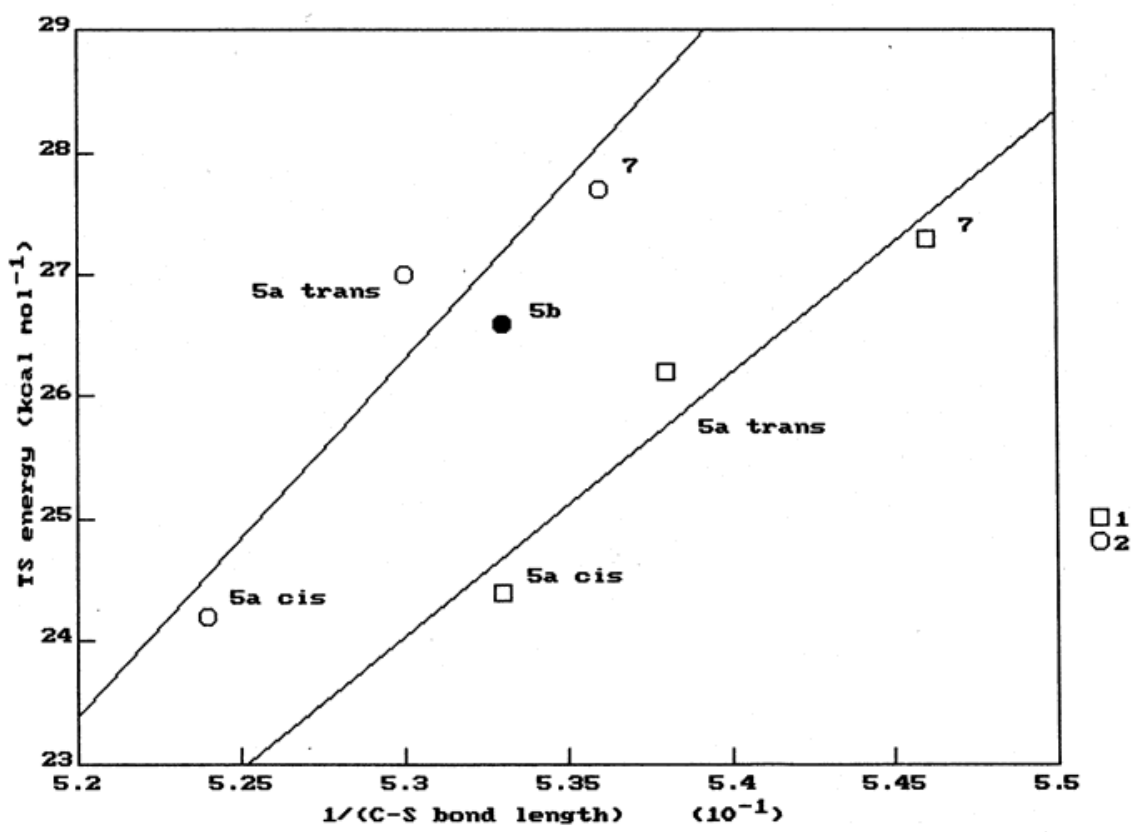

Figure 8. Experimental $(\square)$ and calculated ( $\circ$ and •) interconversion energies for the rearrangements of thiiranium ions $\mathbf{5 a}$ (cis and trans modalities) and $\mathbf{5 b}$ and of thiirenium ion $\mathbf{7}$, correlated with the reciprocals of the cleaved CS bond lengths. The calculated point for the rearrangement of $\mathbf{5 b}$ is skipped from the linear fitting. The correlation coefficients are $\mathrm{r}=0.963$ (experimental points) and $\mathrm{r}=0.945$ (calculated).

The inspection of the x-ray structures of the tetrafluoroborates of $c$-2,t-3-di-tert-butyl-r-1methylthiiranium ion 5a and of 2,3-di-tert-butyl-1-methylthiirenium ion 7 allowed us to came across an empirical correlation between the rearrangement rates documented in Figure 7 and the lengths of the endocyclic CS bonds that will be cleaved during the process. ${ }^{18}$ More correctly, we report in Table 1 and in Figure 8 the correlation of the activation free energies at $298 \mathrm{~K}\left(\Delta G^{\neq}{ }_{298}\right)$ for the processes with the strengths of the breaking CS bond, and therefore with the reciprocals of the bond length (which have the dimension of a wavenumber). The t-2,t-3-di-tert-butyl-r-1methylthiiranium ion $\mathbf{5 b}$ was also was investigated for the occurrence of a similar rearrangement process, which however was obscured by faster competing reactions. ${ }^{12}$ 
The correlation between the $\Delta G^{\neq}$values and the CS bond energies is limited to only three points, but is nevertheless satisfactory. The relationship would suggest that the main factor governing the nucleophilic displacement, both to the $\mathrm{sp}^{3}$ carbon of $\mathbf{5 a}$ and to the $\mathrm{sp}^{2}$ carbon of $\mathbf{7}$, is the nucleofugality of the LG (factor iii above). We have undertaken an ab initio investigation

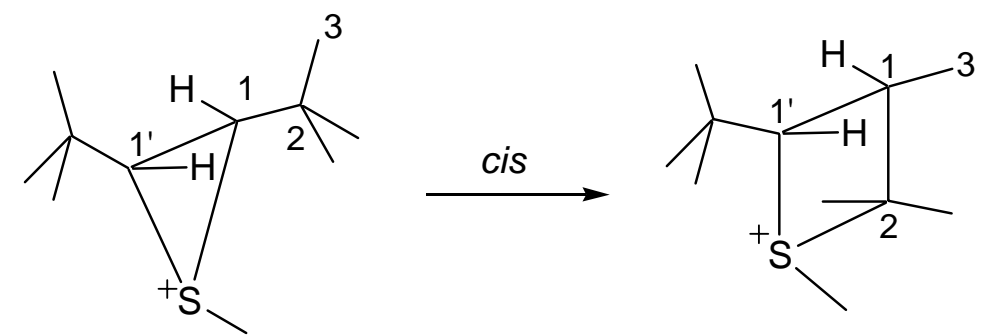

$5 a$

$6 a$

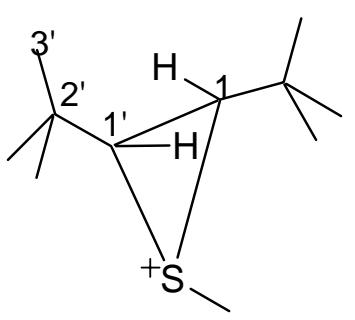

$5 a$

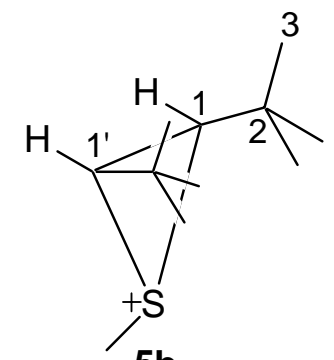

$5 b$

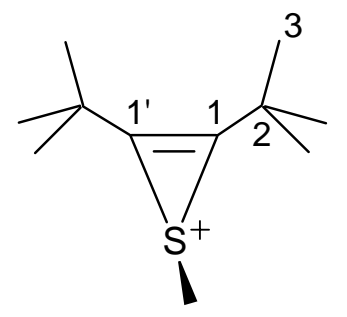

7

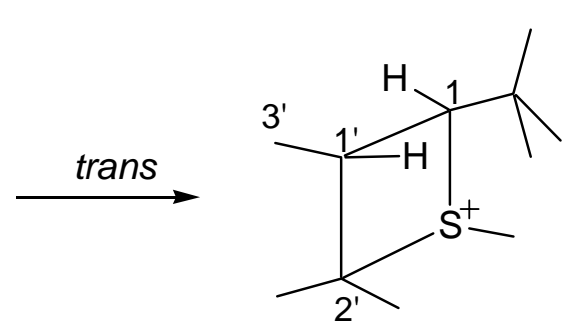

6b

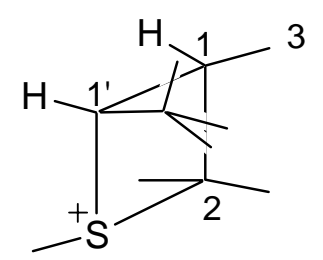

6c

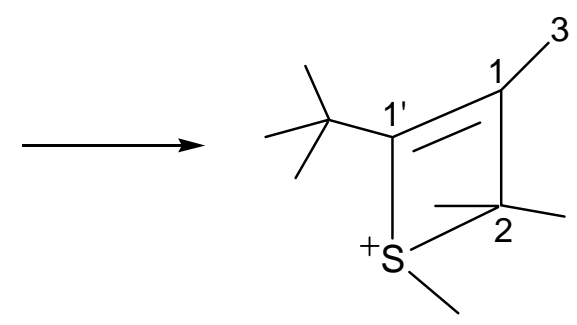

8

Figure 9. The rearrangements of thiiranium ions 5a (cis and trans modalities) and $\mathbf{5 b}$ and of thiirenium ion $\mathbf{7}$ and the corresponding rearranged thietanium ions $\mathbf{6}$ and thietium ion $\mathbf{8}$. The thietanium ions 6a-c are those specifically produced by the "totally" concerted mechanism (see text).

(extended to the rearrangement of thiiranium ion $\mathbf{5 b}$ ) in order to confirm the relationship and to rationalize the rearrangement ordering, in terms of geometrical and stereochemical factors of the 
reagents, as established from the x-ray structures, and in terms of stereoelectronic factors, as deduced from inspection of the $a b$ initio localized transition states for the rearrangements. At the same time, the rationalization will hopefully offer arguments for a comparative discussion of the general $\mathrm{S}_{\mathrm{N}} 2$ and $\mathrm{S}_{\mathrm{N}} 2-\mathrm{V}$ in mechanisms.

\section{Results}

\section{X-ray diffractometric results}

The complete crystallographic data for the tetrafluoroborates of thiiranium ions $\mathbf{5 a}$ and $\mathbf{5 b}$ and of thiirenium ion 7 are published elsewhere. ${ }^{18}$ We collect in Table 1 the geometrical features which are relevant for the following discussion, i.e. the length of the endocyclic CS bond that is subjected to cleavage following the nucleophilic methyl migration, and the dihedral angle $\left(\mathrm{C}_{3} \mathrm{C}_{2} \mathrm{C}_{1} \mathrm{~S}\right.$ and $\left.\mathrm{C}_{3} \mathrm{C}_{2} \mathrm{C}_{1} \mathrm{~S}\right)$ between this bond and the bond within the tert-butyl group which is in the most antiperiplanar orientation. In the same Table we give the $\Delta G^{\neq}$values corresponding to the rate constants for the experimentally determined rearrangements at $298 \mathrm{~K}^{12,13}$

\section{Ab initio computations}

We have utilized throughout the Spartan 4.0 system of programs, taking advantage of the built-in animated display facility for the correct recognition of the transition state structures. ${ }^{19}$

In a first phase of the investigation we assumed "totally" double concerted rearrangements, with synchronous displacement of the methyl $\mathrm{C}_{3}$ antiperiplanar to the $\mathrm{CS}$ bond onto the $\mathrm{C}_{1}$ ring carbon and of the sulfur atom onto the $C_{2}$ quaternary carbon (Figure 9). Therefore, the cis and the trans rearrangements of thiiranium ion $5 \mathbf{a}$ will generate the thietanium ions $\mathbf{6 a}$ and $\mathbf{6 b}$, and that of the thiiranium ion $\mathbf{5 b}$ the thietanium ion $\mathbf{6 c}$, with differently oriented substituents.

The structures and energies of thiiranium ions $\mathbf{5 a}$ and $\mathbf{5 b}$ and of thiirenium ion $\mathbf{7}$ have been computed $a b$ initio at the $\mathrm{HF} / 3-21 \mathrm{G}^{*} / / 3-21 \mathrm{G}^{*}$ level. The computed energies $\left(E_{\mathrm{el}}\right)$ and the relevant $\mathrm{CS}$ bond lengths and $\mathrm{C}_{3} \mathrm{C}_{2} \mathrm{C}_{1} \mathrm{~S}$ or $\mathrm{C}_{3} \mathrm{C}_{2} \mathrm{C}_{1}$ 'S dihedral angles are given in Table 1 . The structures and the energies of thietanium ions 6a-c and of thietium ion $\mathbf{8}$ have been computed at the same level. The energies are reported in Table 1.

The transition states (TS) have been localized at the $3-21 \mathrm{G}^{*}$ level with the linear synchronous transit (LST) approach. ${ }^{20}$ Nine intermediate geometries between that of the reagent and that of the product have been generated. The angle formed by the nucleophilic migrating methyl, the tert-butyl quaternary carbon and the electrophilic adjacent ring carbon $\left(\mathrm{C}_{3} \mathrm{C}_{2} \mathrm{C}_{1}\right.$ or $\mathrm{C}_{3^{\prime}} \mathrm{C}_{2^{\prime}} \mathrm{C}_{1^{\prime}}$ angle in Figure 9) was found to change monotonically, and was taken as reaction coordinate. The intermediate structures have been optimized with this angle kept fixed. The topenergy structure was then subjected unconstrained to the TS search. The localized stationary point was verified as first-order saddle point by calculating the eigenvalues of the Hessian matrix. The animated display of the normal mode of vibration corresponding to the imaginary frequency reveals that the stationary points are indeed the desired TS structures 9a-c and $\mathbf{1 0}$ (in Figure 10). The computed energies are given in Table 1. 


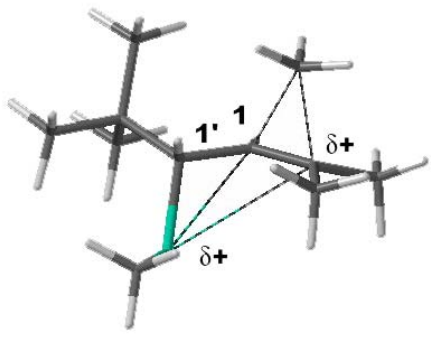

$9 \mathbf{a}$

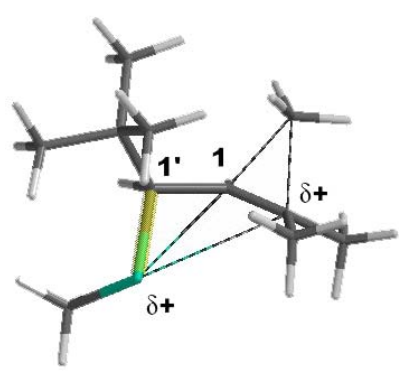

9c

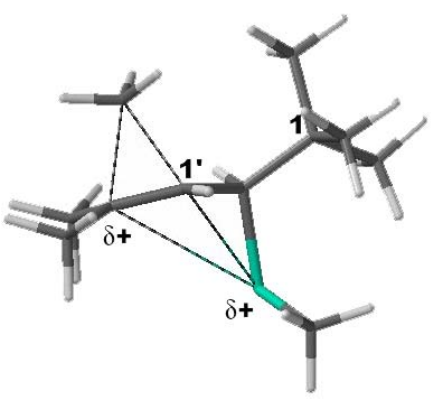

$9 \mathbf{b}$

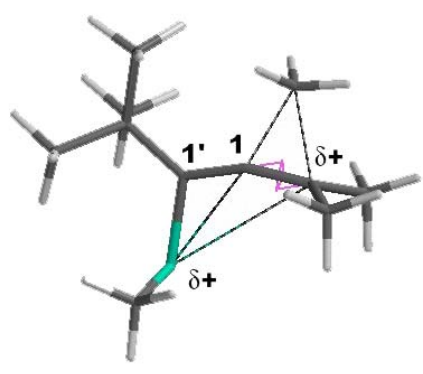

10

Figure 10. Calculated transition states: 9a and 9b (for the cis and trans rearrangements of thiiranium ion 5a respectively), 9c (for the rearrangement of thiiranium ion 5b) and $\mathbf{1 0}$ (for the rearrangement of thiirenium ion 7 ).

An examination of the geometrical features of these TSs highlights $\mathrm{SC}_{1}, \mathrm{C}_{1}$ or $\mathrm{SC}_{1} \mathrm{C}_{1}$, angles that are greater both than the corresponding angles in the thiiranium or thiirenium precursors and than those of the thietanium or thietium products, and probably close to the predictable angles in the postulated carbenium ions intermediates 11 or 12 (Figure 11). Therefore, in a second phase of this investigation, we tried to localize these intermediates, which can be thought to arise from a "partially" concerted mechanism, with synchronous attack of the methyl and cleavage of the CS bond.

The gauche rotamers 11a-c are those immediately generated by the "partially" concerted mechanism in the rearrangement of thiirenium ions $\mathbf{5 a}$ and $\mathbf{5 b}$. These rotamers could not be localized: the optimization process invariably collapses to the geometries of the thietanium ions 6a-c. The rotamers 11a-c therefore are not singular points in the energy hypersurface describing the rearrangement process. On the contrary, the geometries of the non-immediate anti rotamers 11'a-c, with antiperiplanar orientation of the carbenium ion and of the sulfide group, could be regularly optimized. 
Using the same arguments, in the rearrangement of thiirenium ion 7 the "partially" concerted mechanism should initially lead to the "perpendicular" $\alpha, \beta$-unsaturated carbenium ion 12, which may be considered the high energy rotamer of the allyl cation 12'. Again, the optimization of 12 ends with the geometry of the thietium ion $\mathbf{8}$, while the geometry of the allyl cation 12' is achieved without a problem.

\section{Discussion}

The nature of the transition state and the non-existence of the carbenium ion intermediates The "totally" concerted cis and trans rearrangements of thiiranium ion 5a will generate the thietanium ions $\mathbf{6 a}$ and $\mathbf{6 b}$ with $S$-methyl and tert-butyl groups respectively trans and cis oriented. From the HF/3-21G*//3-21G* optimizations, the thietanium ion $\mathbf{6 a}$ is calculated as the most stable. This is also the only species that has been detected following the experimentally monitored rearrangements of $\mathbf{5 a}$, either with cis or with trans modality. ${ }^{12,21}$ The intermediacy of carbenium ions 11a and 11b (Figure 11) was therefore assumed, ${ }^{12}$ where the free rotation of the $S$-methyl moiety will assure a ring closure toward the most stable thietanium ion 6a. The rearrangement of thiiranium ion $\mathbf{5 b}$ will generate the thietanium ion $\mathbf{6 c}$ only.

The intermediates 6a-c, which are formed by the "partially" concerted mechanism as gauche rotamers, require the same rotameric orientation for the closure to thietanium ions. As anticipated in the Results, the search at the $3-21 G^{*} / / 3-21 G^{*}$ level for these rotamers failed.imilar considerations hold for the rearrangement of thiirenium ion $\mathbf{7}$ to thietium ion $\mathbf{8}$. The intermediate generated from the "partially" concerted mechanism, the $\alpha, \beta$-unsaturated carbenium ion 12, has the correct geometry for the closure to thietium ion $\mathbf{8}$, but could not be located.

Nevertheless, the inspection of the animated displays of the normal mode of vibration associated to the imaginary frequency suggests that the computed TSs may well be those connecting thiirenium ions $\mathbf{5 a}$ and $\mathbf{5 b}$ and the gauche carbenium ions 11a-c, and that connecting thiirenium ion 7 and the "perpendicular" $\alpha \beta$ unsaturated carbenium ion 12. This is also confirmed by the $\mathrm{C}_{1} \mathrm{C}_{1}, \mathrm{~S}$ or $\mathrm{C}_{1}, \mathrm{C}_{1} \mathrm{~S}$ angles in TSs 9a-c and $\mathbf{1 0}$ (Table 1), which are higher both than those of thiiranium ions $\mathbf{5 a}$ and $\mathbf{5 b}$ or of thiirenium ion $\mathbf{7}$ and than those of thietanium ions 6a-c and thietium ion 8, but close to corresponding computed angles in the carbenium ions 11'ac and in the allyl cation 12'.

We can conclude that the proximity of electrophilic carbenium atom and nucleophilic sulfur atom prevents the "gas-phase" existence of the gauche rotamers 11a-c and of the unsaturated carbenium 12.

The correspondence of the calculated TSs 9a-c and $\mathbf{1 0}$ to the experimental TSs for the actually observed rearrangements is substantiated by the comparison, although indirect, between the experimental activation free energies $\left(\Delta G^{\neq}\right)$and the calculated activation electronic energies $\left(\Delta E_{\mathrm{el}}\right)$ for the rearrangement processes (Table 1 and Figure 8$)$. 


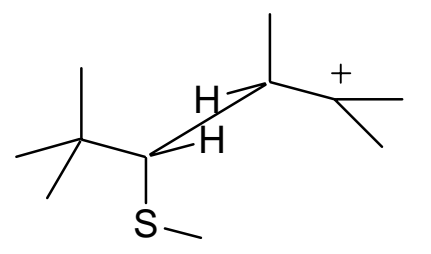

$11 \mathrm{a}$

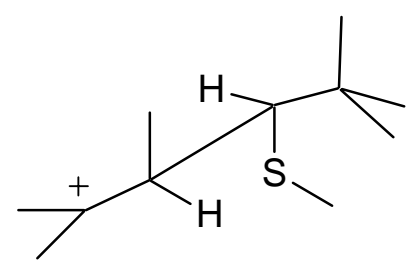

11b

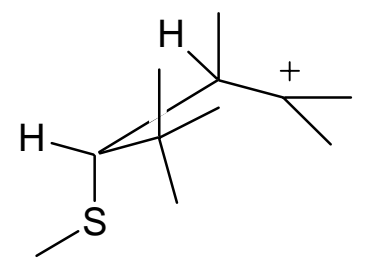

$11 \mathrm{c}$

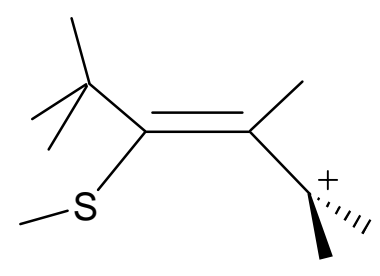

12
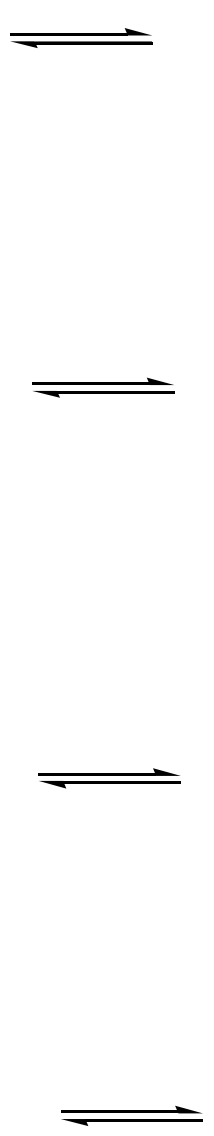

Figure 11. The optimizations of the gauche carbenium ions 11a-c and of the "perpendicular" usaturated carbenium ion 12 degenerate into thietanium ions 6a-c and into thietium ion $\mathbf{8}$. The anti rotamers 11'a-c and the allyl cation 12' can be optimized, but do not belong to the rearrangement paths.

\section{The requirement of antiperiplanarity}

Intramolecular nucleophilic displacements are subjected to the requirement of antiperiplanarity between the bond of the migrating nucleophile and that of the LG. This requirement does not represent a discriminating factor which could explain the ordering of the experimental free activation energies or the ordering of the calculated electronic activation energies: for every rearrangement process it is possible to recognize, both in the x-ray structures and in the $a b$ initio optimized geometries of 5a, $\mathbf{5 b}$ and $\mathbf{7}$, a methyl group which forms with the detaching sulfur a dihedral angle very close to $180^{\circ}$. 


\section{The correlation with the bond lengths at the LG}

The experimental $\Delta G^{\neq}$values for the rearrangements in Figure 8 cannot be directly compared with the computed activation electronic energies $\Delta E_{\mathrm{el}}$, not corrected for the entropy contribution and for the zero-point energy (ZPE). Nevertheless they show similar trends, suggesting that these factors do compensate.

More meaningful correlations are found with the lengths of the bonds between the electrophilic ring carbon and the sulfur LG or, more correctly, with the reciprocals of these lengths (which, having the dimension of a wavenumber, measure the bond energies). The correlations are displayed in Figure 8. Both correlations, experimental and computed, show a monotonic, almost linear, dependence of the activation energies with the reciprocals of the bond lengths, provided that the calculated point for the rearrangement of thiiranium ion $\mathbf{5 b}$ is skipped. This exclusion is reasonable: the steric hindrance between the co-oriented tert-butyl groups makes this ion less stable than the 5a isomer (c.f. Table 1), with the consequence of a more relevant steric release upon rearrangement and a corresponding lower activation energy. The experimental observation of the rearrangement of $\mathbf{5 b}$ has been prevented by competing reactions at the ring carbons, which are less shielded to the attack of external nucleophiles than those of the other thiiranium ion 5 a or of thiirenium ion $7 .^{12}$

The natural atomic charges at sulfonium sulfur (Table 1) do not seem to play any role as a measure of the LG nucleofugality.

\section{The comparison of the $S_{N} 2$ and $S_{N} 2-V i n$ mechanisms}

The most discriminating factors governing the $\mathrm{S}_{\mathrm{N}} 2$ and the $\mathrm{S}_{\mathrm{N}} 2$-Vin mechanisms are the different steric hindrances to the approaching nucleophile exerted by substituents that are below or above the approach plane in the case of the $\mathrm{S}_{\mathrm{N}} 2$ mechanism, but lie exactly in this plane in the case of the $\mathrm{S}_{\mathrm{N}} 2$-Vin mechanism. The choice, as a case study, of the intramolecular anionotropic methyl migration in thiiranium ions $\mathbf{5 a}$ and $\mathbf{5 b}$ and in thiirenium ion $\mathbf{7}$ completely removes this factor, so that we can take into consideration only the electronic factors.

The good correlations shown in Figure 8 (but for the rearrangement of 5b) suggest that the two mechanisms are essentially governed by the nucleofugality of the LG, as measured by the strength of the bond with the electrophilic ring carbon. It is easy to account for the strengths (or lengths) of these bonds. The $\mathrm{SC}_{1}$ bond in thiiranium ion 5a is lengthend, with respect to the other $\mathrm{SC}_{1}$, bond, by the non bonding repulsion between $S$-methyl and cis oriented tert-butyl. The ring SC bonds in thiirenium ion 7 are shortened by the contribution of the mesomeric structures shown in Figure 12.

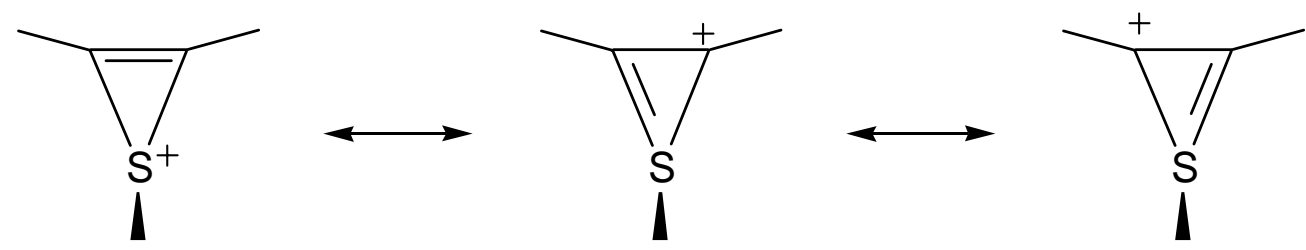

Figure 12. Mesomeric structures of thiirenium ring. 

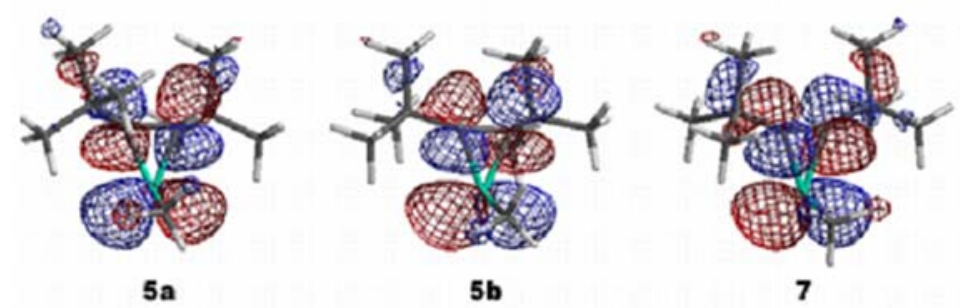

Figure 13. Shapes of LUMO of thiiranium ions $\mathbf{5 a}$ and $\mathbf{5 b}$ and of thiirenium ion $\mathbf{7}$, calculated $a b$ initio at the 3-21G*//3-21G* level.

At the same time, the mesomeric description of 7 should imply a greater positive charge (or a lower negative charge) at ring carbons (i.e. higher electrophilicities). The $3-21 \mathrm{G}^{*}$ natural atomic charges of ring carbons are significantly increased in thiirenium ion 7 with respect to those of thiiranium ions $\mathbf{5 a}$ and $\mathbf{5 b}$ (Table 1). The higher electrophilicity of the ring carbons of $\mathbf{7}$ should somehow boost the nucleophile approach and lower the activation energy for the rearrangement. This fact, which is perhaps manifested in Figure 8, is nevertheless of limited importance.

The LUMO's of thiiranium ions $\mathbf{5 a}$ and $\mathbf{5 b}$ and of thiirenium ions $\mathbf{7}$ (shown in Figure 13) have the same shapes (they are Walsh type orbitals) and roughly the same energies (Table 1$):^{22}$ the HOMO(nucleophile)-LUMO(electrophile) interaction is therefore a non discriminating factor. The inversion of configuration is reported to be energetically more favoured at an $\mathrm{sp}^{3}$ that at an $\mathrm{sp}^{2}$ carbon atom. ${ }^{17}$ On the contrary, the release of steric strain will favour the opening of a thiirenium ring over that of a thiiranium ring. If these two factors will play a role, it is not such as to significantly alter the ordering of the reaction rates.

\section{Conclusions}

The above considerations make the $\mathrm{S}_{\mathrm{N}} 2$ mechanism in thiiranium ion 5a and and $\mathrm{S}_{\mathrm{N}} 2$-Vin mechanism in thiirenium ion 7 very similar from a stereoelectronic point of view, because the intramolecular nature of the rearrangements equalizes the steric effects. Both mechanisms are governed by the nucleofugality of the sulfonium LG, measured by the strength of the cleaving bond.

It remains to assess whether this similarity can be carried over to the cases of intermolecular nucleophilic attacks to acyclic $\mathrm{sp}^{3}$ and $\mathrm{sp}^{2}$ carbons (Figure 1). The single most relevant factor which will make the $\mathrm{S}_{\mathrm{N}} 2$-Vin mechanism so seldom observed is the steric hindrance opposed by the geminal substituent to the incoming nucleophile. ${ }^{23}$ The hindrance may shift the interaction of the nucleophile from the low-lying vacant $\sigma$ orbital to the $\pi$ one, i.e. from the $\mathrm{S}_{\mathrm{N}} 2$-Vin mechanism to the $\mathrm{Ad}_{\mathrm{N}} \mathrm{E}$ one. When the hindrance is avoided (this may be technically feasible only in intramolecular rearrangements) and the LUMO of the vinyl system has the correct $\sigma$ symmetry, the stereoelectronic similarity may come into light. 


\section{References}

1. (a) Modena, G. Acc. Chem. Res. 1971, 4, 73. (b) Rappoport, Z. Acc. Chem. Res. 1981, 14, 7. (c) Rappoport, Z. Recl. Trav. Chim. Pays-Bas 1985, 104, 309. (d) Rappoport, Z.; Gazit, A. J. Org. Chem. 1986, 51, 4112.

2. Rappoport, Z. Adv. Phys. Org. Chem. 1969, 7, 1.

3. (a) Gold, V. J. Chem. Soc. 1951, 1430. (b) Subramanian, L. R.; Hanack, M. J. Chem. Educ. 1975, 52, 80 .

4. Isaacs, N. S. Physical Organic Chemistry; Longman Scientific \& Technical: Harlow, GB, 1987, p 383.

5. Lucchini, V.; Modena, G.; Pasquato, L. J. Am. Chem. Soc. 1995, 117, 2297.

6. (a) Rappoport, Z. Tetrahedron Lett. 1978, 1073. (b) Capozzi, G.; Lucchini, V.; Modena, G. Rev. Chem. Intermed. 1979, 4, 347.

7. Bassi, P.; Tonellato, U. J. Chem. Soc., Perkin Trans. 2 1974, 1283.

8. McManus, S. P.; Neamati-Mazreah, N.; Paley, M. S.; Hovanes, B. A.; Harris, J. M. Tetrahedron. Lett. 1985, 26, 4571.

9. Stang, P. J.; Dueber, T. E. J. Am. Chem. Soc. 1977, 99, 2602.

10. Lucchini, V.; Modena, G.; Zaupa, T.; Capozzi, G. J. Org. Chem. 1982, 47, 590.

11. Modena, G.; Rivetti, F.; Tonellato, U. J. Org. Chem. 1978, 43, 1521.

12. (a) Lucchini, V.; Modena, G.; Pasquato, L. J. Am. Chem. Soc. 1988, 110, 6900. (b) Lucchini, V.; Modena, G.; Pasquato, L. J. Am. Chem. Soc. 1991, 113, 6600.

13. Lucchini, V.; Modena, G.; Pasquato, L. J. Am. Chem. Soc. 1993, 115, 4527.

14. Burighel, A.; Modena, G.; Tonellato, U. J. Chem. Soc., Perkin Trans. 2 1972, 2026.

15. (a) Solvolysis of aliphatic substrates: Noyce, D. S.; Virgilio, J. A. J. Org. Chem. 1972, 37, 2643. (b) Solvolysis of vinylic substrates: Modena, G.; Tonellato, U. Adv. Phys. Org. Chem. 1971, 9, 246.

16. The steric hindrance of the in-plane substituent, greater for the in-plane approach of the nucleophile than for the perpendicular approach, is one argument that favours the $\operatorname{Ad}_{\mathrm{N}}-\mathrm{E}$ mechanism rather than the $\mathrm{S}_{\mathrm{N}} 2$-Vin one: Miller, S. I.; Yonan, P. K. J. Am. Chem. Soc. 1957, 79, 5931.

17. Cf. the energetics for pyramidal inversion of trialkylamines and for in-plane inversion of imines: Koeppl, G. W.; Sagatys, D. S.; Krishnamurthy, G. S.; Miller, S. I. J. Am. Chem. Soc. 1967, 89, 3396.

18. Destro, R.; Lucchini, V.; Modena, G.; Pasquato, L. J. Org. Chem. 2000, 65, 3367.

19. Spartan 4.0 program system, distributed by Wavefunction, Inc., Irvine CA 92715.

20. Halgren. T. A.; Lipscomb, W. N. Chem. Phys. Lett. 1977, 49, 225.

21. Destro, R.; Ortoleva, E.; Modena G.; Pasquato, L.; Lucchini, V. Helv. Chim. Acta 2001, 84, 1860.

22. Fachini, M.; Lucchini, V.; Modena, G.; Pasi, M.; Pasquato, L. J. Am. Chem. Soc. 1999, 121, 3944.

23. The theoretical investigation of the identity reaction of chloride ion attack to unsubstituted vinyl chloride found that the $\mathrm{S}_{\mathrm{N}} 2$-Vin transition state is energetically more accessible than the $\mathrm{Ad}_{\mathrm{N}}-\mathrm{E}$ intermediate. The governing factor may be the reduced steric hindrance of the 
geminal hydrogen atom: Glukhovtsev, M. N.; Pross, A.; Radom, L. J. Am. Chem. Soc. 1994, 116, 5961. 